\title{
Lenguaje: GU o no ser, esa es la cuestión ${ }^{1}$
}

\author{
Johan J. Bolhuis \\ Departments of Psychology and Biology, Utrecht University
}

Division of Anthropology, American Museum of Natural History, New York

Noam Chomsky

Department of Linguistics and Philosophy, MIT, Cambridge, Massachusetts

Robert C. Berwick
Department of Electrical Engineering \& Computer Science and Brain and Cognitive Sciences,
MIT

El comentario de Lieberman [1] ilustra bien nuestro argumento original [2] de que el análisis de la evolución del lenguaje se complica por la ausencia de consenso entre los conceptos de "lenguaje" y "evolución". Nos ocuparemos aquí de cada uno de ellos de manera independiente. En primer lugar, Lieberman argumenta en contra de la existencia de una facultad de lenguaje en el sentido en que la definimos, es decir, como un sistema cognitivo computacional específico de dominio y de especie que puede generar una estructura sintáctica jerárquica arbitrariamente compleja. En contraste, Lieberman define el lenguaje funcionalmente, esto es como un medio de "comunicación", siendo el habla humana un "atributo clave". Sin embargo, como argumentamos originalmente [2], mientras que el lenguaje externalizado puede ser utilizado para la comunicación, los dos no pueden ser equivalentes. El lenguaje es una operación computacional que tiene lugar en la mente de un individuo, independientemente de su posible uso comunicativo, mientras que el habla es una posible externalización del lenguaje (entre otros los signos manuales) y no es un aspecto esencial del mismo. Los argumentos de Lieberman son un ejemplo primordial de la confusión falaz de la(s) función (es) de un rasgo con su respectivo mecanismo [3,4].
Según Lieberman [1], el lenguaje es esencialmente comunicación hablada, con una estructura jerárquica compartida con otras habilidades motrices como el baile. Desde este punto de vista, las reglas para la organización jerárquica de los elementos léxicos se adquieren por medio del aprendizaje motor asociativo, del mismo modo que los humanos aprenden a caminar o a usar cubiertos. Esto contrasta con nuestra opinión [2,5] de que los niños pueden adquirir cualquier idioma ya que poseen una gramática universal (GU) [5-8]. Lieberman argumenta en contra de la operación básica que llamamos "fusión" porque, según él, lenguas distintas combinan palabras de manera diferente. En su opinión, aparentemente, la estructura sintáctica jerárquica se genera de manera diferente en cada lengua. Por el contrario, la Tesis Minimalista Fuerte (TMF) sostiene que la operación básica de fusión es suficiente para lograr oraciones jerárquicamente estructuradas en cualquier lengua [5 - 8]. En nuestro ensayo [2] planteamos que "la fusión puede aplicarse fundamentalmente a los resultados de su propia producción", y mostramos que esta característica recursiva conduce a las expresiones jerárquicas potencialmente ilimitadas características del lenguaje humano, cada una de las cuales es sistemáticamente interpretada en la interfaz

1 Bolhuis JJ, Tattersall I, Chomsky N, Berwick RC (2015) Language: UG or Not to Be, That Is the Question. PLoS Biol 13(2):e1002063.doi:10.1371/journal.pbio.1002063. Correo electrónico de contacto: jj.bolhuis@uu.nl 
conceptual-intencional, es decir, interna a la mente-cerebro, no sólo externalizada como habla. El énfasis en el habla y en el tracto vocal no es relevante; como lo demostró Lenneberg [9] hace casi 50 años, quienes aprenden lengua de signos adquieren y utilizan la muestra apenas como hacen los hablantes. Abundantes ejemplos empíricos muestran que este tipo de estructura integra los cálculos mentales internos del lenguaje, tanto en inglés como en otras lenguas (por ejemplo, [10]). Así, la estructura sintáctica jerárquica, no lineal, determina que "él" y "Juan" no pueden ser la misma persona en "Él dijo que Juan encargó sushi", pero puede ser el mismo en "Mientras estaba sosteniendo la pasta, Juan ordenó sushi". La restricción relevante no es el orden lineal de "él" y "Juan", es decir, que un pronombre sólo puede identificarse con un nombre solamente si aparece después del nombre en orden de izquierda a derecha. Más bien, si es un pronombre mantiene una relación estructural jerárquica particular con un nombre. Además, precisamente la misma restricción jerárquica opera en muchos fenómenos lingüísticos aparentemente distintos en todas las lenguas que han sido ampliamente estudiadas: la manera en que se forman las preguntas, la interpretación de la disyunción, la legitimación de los elementos negativos y el "ligamiento" entre nombres y pronombres. Esta confluencia de restricciones por lo demás dispares se explica fácilmente al postular la fusión jerárquica, como cabría esperar de cualquier teoría científica. Pero sigue siendo un enigma si se asume una mera asociación lineal del tipo que Lieberman sugiere. Además, un operador de composición jerárquica se encuentra en el corazón de la mayoría de las teorías lingüísticas contemporáneas: gramática léxico-funcional, gramática sintagmática nuclear, gramática categorial combinatoria, gramática de adjunción de árboles, etc. Todas ellas contienen la operación de fusión, que simplemente identifica esta propiedad común de la composición jerárquica sintáctica que aparece en todas esas teorías, el núcleo de la computación del lenguaje humano.

Lieberman también equipara los "procesos darwinianos" con una selección natural gradual. Esta simplificación excesiva no cuadra con el patrón episódico empíricamente observado en la evolución biológica y tecnológica humana [11]. Tampoco su especulación de que los neandertales tenían "sintaxis simple" es apoyada por cualquier evidencia de primates no humanos $[5,12]$. Además, su afirmación de que la transmisión de las destrezas para producir la tecnología lítica Levallois habilidades de fabricación de herramientas requiere de lenguaje es contradicha por el experimento [13]. Por el contrario, el patrón típico de estasis en la tecnología de herramientas de piedra antes del surgimiento del Homo sapiens moderno demuestra una falta de lenguaje hasta hace muy recientemente $[11,14]$, mientras que el tracto vocal moderno fue adquirido antes de que tuviéramos una razón sustancial para suponer que fue reclutado para el habla. Con su énfasis en el habla y el aprendizaje motor, Lieberman hace gran énfasis en el papel de FOXP2 en los circuitos neuronales implicados en el control motor. Pero destacar sólo un gen un único factor de transcripción- es extraño [2]. Lo que sostenemos en nuestro ensayo, es, sin embargo, que el habla no es lo mismo que el lenguaje. La relación entre los genes y el fenotipo computacional y cognitivo que llamamos lenguaje es seguramente compleja y se extiende a través de una serie de etapas intermedias, incluidas las que implican neuronas y circuitos cerebrales. Las mutaciones o desactivaciones de FOXP2 pueden tener efectos sobre los sistemas motores, incluyendo las vocalizaciones, en una gama de diversos animales [15]. Pero nada de esto es relevante con respecto al núcleo computacional de la sintaxis, la operación de fusión; más bien, afecta al sistema de "entrada-salida", pero no al procesador central. Por supuesto, como hemos venido argumentado, es bastante plausible que este sistema computacional podría haber estado vinculado a "posibles mecanismos perceptivos y motores preexistentes" [2], mientras que las mutaciones tanto en FOXP2 como en otros genes pueden haber jugado un papel en la evolución de estos mecanismos. Pero esto supone simplemente la preadaptación de un sustrato de entradasalida, tal como se encuentra comúnmente en la evolución.

Por lo tanto, mantenemos nuestro argumento clave [2] que la evidencia paleoantropológica 
que sugiere que la facultad de lenguaje surgió hace unos 70.000-100.000 años es totalmente coherente con la manera simple en que la Tesis Minimalista Fuerte define la sintaxis del lenguaje.

\section{Referencias bibliográficas}

[1] Lieberman P (2015) Language did not spring forth 100,000 years ago. PLoS Biol 13(2): e1002064. Doi: 10.1371/journal. pbio.1002064.

[2] Bolhuis JJ, Tattersall I, Chomsky N, Berwick RC (2014) How could language have evolved? PLoS Biol 12(8):e101934.

[3] Bolhuis JJ, Wynne CDL (2009) Can evolution explain how minds work? Nature 458: 832833. Doi: 10.1038/458832a. PMID: 19370014

[4] Bolhuis JJ, Brown GR, Richardson RC, Laland KN (2011) Darwin in mind: New opportunities for evolutionary psychology. PLoS Biol 9 (7): e1001109. Doi: 10.1371/ journal.pbio.1001109. PMID: 21811401

[5] Berwick RC, Friederici AD, Chomsky N, Bolhuis JJ (2013) Evolution, brain, and the nature of language. Trends Cogn Sci 17: 8998. Doi: 10.1016/j.tics.2012.12.002. PMID: 23313359

[6] Chomsky N (2000) Minimalist inquiries: The framework. In: Martin R, Michaels D, Uriagereka J, editors. Step by step: Essays on minimalist syntax in honor of Howard Lasnik. Cambridge (Massachusetts): MIT Press. pp. 89-155. PMID: 1716050

[7] Berwick R, Chomsky N (2011) The biolinguistic program: The current state of its development. In: Di Sciullo AM, Boeckx $\mathrm{C}$, editors. The biolinguistic enterprise.
Oxford: Oxford University Press. pp. 1941.

[8] Chomsky N (2013) Problems of projection. Lingua 130: 33-49.

[9] Lenneberg E (1967) Biological Foundations of Language. New York: John Wiley.

[10] Crain S (2012) The Emergence of Meaning. Cambridge: Cambridge University Press.

[11] Tattersall I (2012) Masters of the Planet. The Search for our Human Origins. Palgrave Macmillan.

[12] Yang C (2013) The ontogeny and phylogeny of language. Proc Natl Acad Sci USA 110: 6324-6327. Doi: 10.1073/pnas.1216803110. PMID: 23576720

[13] Ohnuma K, Aoki K, Akazawa T (1997) Transmission of tool-making through verbal and non-verbal communication: Preliminary experiments in Levallois flake production. Anthropol Sci 105: 159-168.

[14] Tattersall I (2014) An evolutionary context for the emergence of language. Lang Sci 46: 199-206. Doi: 10.1017/S0021932013000266. PMID: 23702355

[15] Bolhuis JJ, Okanoya K, Scharff C (2010) Twitter evolution: Converging mechanisms in birdsong and human speech. Nat Rev Neurosci 11: 747-759. Doi: 10.1038/nrn2931. PMID: 20959859

Versión española de Miguel Ángel Mahecha (Universidad Surcolombiana, Colombia) $\mathcal{E}$ Víctor Longa (Universidad Santiago de Compostela, España), 2017. 